\title{
Análisis de algunos planteamientos de gestión cultural salvadoreña
}

Amparo Marroquín Parducci

Departamento de comunicaciones

UCA, San Salvador

Lo que parece decadencia de la cultura es su puro llegar a sí misma.

Theodor Adorno

Allá donde el hombre esté más implicado en intensificar la vida en vez de meramente vivirla podremos bablar de un comportamiento estético.

Jordi Claramonte

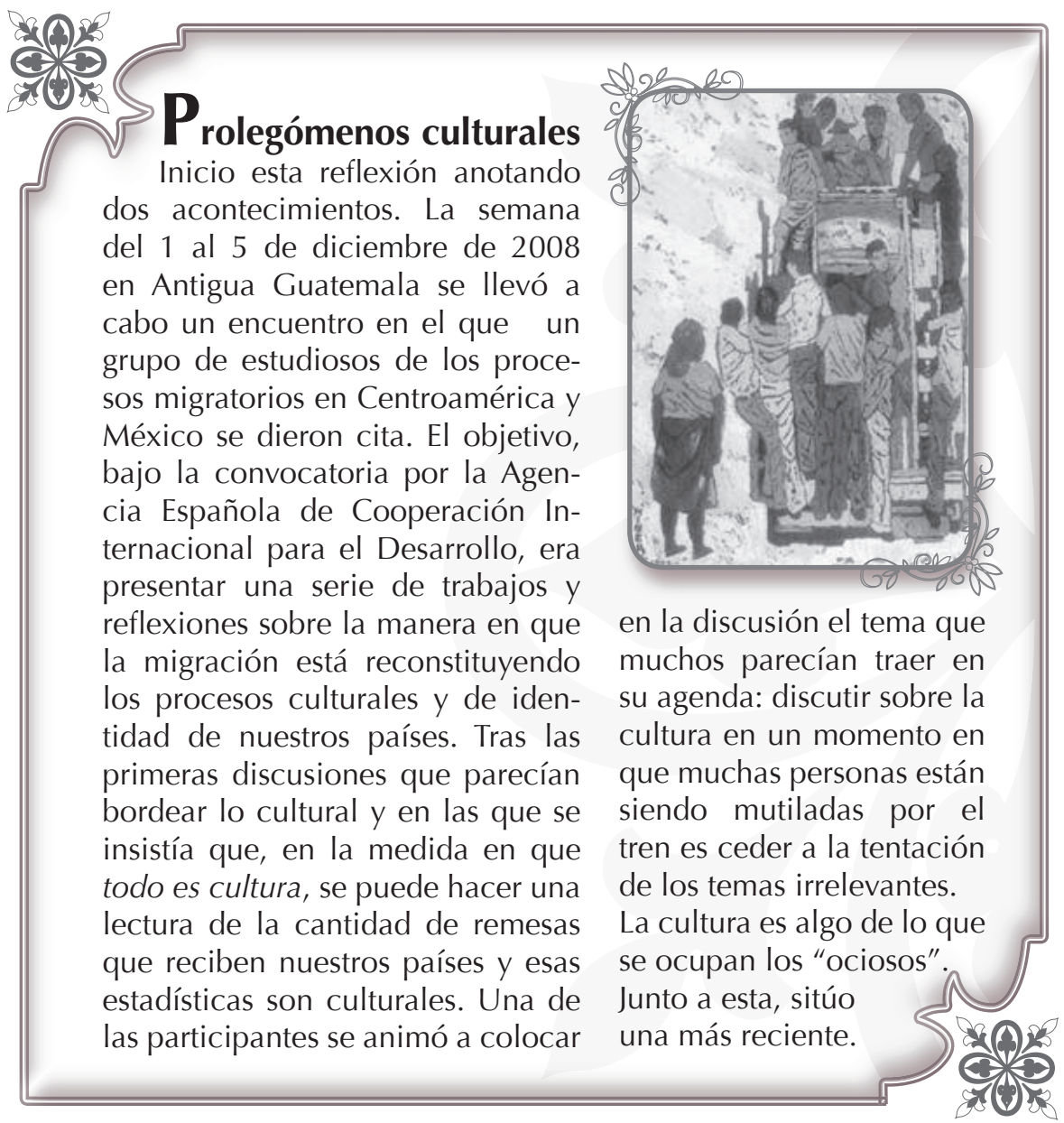


E I 26 y 27 de marzo de 2009 compartí con un grupo interesante de gestores y trabajadores culturales un taller sobre Gestión y dirección de centros culturales, en el Centro Cultural de España. Una de las primeras preguntas que el grupo colocó es si es posible que alguien que no es artista gestione la cultura. Esto llevaba a un presupuesto de fondo: la cultura es, indudablemente, patrimonio, proyecto, intervención, propuesta de los artistas.

Estas dos anécdotas sitúan la argumentación con la que quiero iniciar este texto. Esa sensación que se vive en nuestros países de que la cultura es uno de esos problemas secundarios y de los que podemos ocuparnos después. Una visión donde la Cultura, tal y como fue construida por ciertos planteamientos de la modernidad, reducida al arte, preocupada, como señaló Kant en el XVIII, por lo bello y lo sublime. Capaz de llevarnos a la trascendencia.

Quizá es por ello que el Consejo Nacional para la Cultura y el Arte (CONCULTURA) recibió, en la última gestión, un $0.004 \%$ del Presupuesto General de la Nación para atender sus casi 200 casas de la cultura en el país y en Estados Unidos, Ilevar a cabo publicaciones o trabajar en investigaciones antropológicas y arqueológicas que permitan comprender mejor nuestros procesos culturales. Puede que con ello se explique que durante la presentación del documento "La cultura, apuesta nacional" (2008) ${ }^{1}$, los únicos funcionarios presentes pertenecían a CONCULTURA. Ni el presidente de la República, la Vicepresidenta o al menos el Ministro de Turismo (que de hecho es parte del Consejo Técnico Consultivo) se encontraban presentes para dar fe que, en efecto, la cultura es una apuesta del gobierno. Se encontraban algunos representantes de la sociedad civil, pero sobre todo del gremio artístico, más que de otros sectores que llevaran a pensar que la cultura es entendida como un proceso amplio, anclado en las construcciones y la simbolización de las personas en su vida cotidiana. También quizá es por esta visión de cultura como algo reducido y nada urgente que el Plan de Gobierno presentado por el Frente Farabundo Martí para la Liberación Nacional (FMLN) (Martínez, 2008) para estas nuevas elecciones divide su propuesta en cuatro partes, ninguna de las cuales hace alusión explícita al ámbito de lo cultural ${ }^{2}$, que más bien será un subcomponente del análisis y al que se le dedicarán una página y media explícita de las 106 que conforman el documento. Posiblemente esta manera de situarse un país ante la realidad cultural lleve a que un periódico como La Prensa Gráfica recorte su sección cultura, que (independiente de las críticas que podían hacerse a ese tipo particular y reducido de periodismo cultural) ha pasado a ser una sección esporádica.

Este es pues el punto de partida del presente ensayo. La cultura no se encuentra situada en la agenda 
pública como una discusión fundamental de la sociedad salvadoreña. Mientras se nos va el día a día en resolver los problemas de la economía, la crisis o de la inseguridad,; mientras analizamos desde las categorías políticas lo que implica este cambio en el gobierno, hemos dejado ya de preguntarnos qué tipo de sociedad queremos vivir y en qué tipo de nación nos hemos venido constituyendo. Hemos dejado de preguntarnos por la memoria que nos es común y el olvido que hemos buscado, los gestos, los sueños, los placeres o dolores que nos hacen sentirnos parte de un colectivo. No sabemos si queremos o no conservarlos y en algunos momentos se escuchan voces de alerta que hablan de cómo cierta "identidad", en el fondo desconocida, se nos escapa de las manos. En estos momentos en el que el país entra a un nuevo momento en su proceso de construcción democrática, bien vale la pena discutir sobre los procesos de simbolización que nos constituyen, y hacia dónde queremos Ilevarlos.

$Y$ este es el punto de llegada. Una provocación. Hace ya varios años, en 1987, el filósofo colombiano-español Jesús Martín Barbero (1998), escandalizó a algunos, señalando en el campo de la comunicación lo que ya otros habían mencionado desde otras disciplinas: que en su concepción teórica sobre la masificación de la sociedad, tanto la izquierda como la derecha tenían una visión muy similar. Si para los marxistas la cul- tura deviene ideología y alienación, para los conservadores la sociedad de masas devino en decadencia y pérdida de valores. En ambos casos la condena a cierto ámbito de lo cultural estético es notoria.

Al revisar los dos planes de cultura, el establecido por el gobierno anterior desde CONCULTURA y la breve propuesta enunciada por el plan de gobierno del nuevo gobierno del FMLN, se encuentran algunas divergencias sobre acciones específicas, pero también se encuentran una serie de semejanzas fundamentales que pasan por dos sitios: primero, una serie de enunciados que visibilizan claramente el ámbito de las artes como el sector fundamental de los procesos culturales. Al visibilizar este ámbito, se invisibilizan otros fundamentales como las industrias culturales, que si bien en el país son mínimas, no son consideradas como un ámbito de intervención, o visibilizan ciertos ámbitos de lo popular y el folklore, pero no se consideran como parte de lo cultural: ámbitos como la ciencia (que es objeto de análisis separados, como si la técnica y ciertos procesos de saber no construyeran cultura).

La segunda convergencia en las propuestas establecidas, tanto desde la derecha como la izquierda política, es considerar una visión cultural que privilegia el aprendizaje formal de las artes como un ámbito serio, sistemático, estructurado ${ }^{3}$, que por un lado vuelve a considerar la cultura como un proceso de "dis- 
tinción" (Bourdieu, 2002) y por el otro deja de lado el ámbito de lo sensorial y lo dionisíaco como un elemento innegociable de la experiencia estética.

Este ensayo consta de tres partes. Las consideraciones iniciales que muestran el punto de partida: la cultura como un ámbito poco discutido y considerado de la vida nacional, luego un breve análisis de los dos documentos y sus propuestas de gestión cultural, una revisión de cómo desde la política se sigue privilegiando la visión moderna que los ilustrados construyeron de la cultura durante los siglos XVII y $X V I I I$, pensando que esa cultura nos Ilevaría al progreso, una Cultura, en singular y en mayúscula, que se discute desde el lenguaje escrito, que invisibiliza y niega las muchas y múltiples oralidades, para finalizar con una primera propuesta de qué acciones deberían ser consideradas en la discusión sobre cultura. Para ello se propone un decálogo inicial, más que con un sentido de mandamientos o dogmas, como un ejercicio de reflexión y provocación.

\section{Las propuestas políticas}

A otro nivel ciertamente, pero en una dirección bien cercana, se halla la condena que hace Lukács de la modernidad por disolver la forma y mezclar, confundir los géneros. Los parecidos con la apocalíptica y conservadora teoría de la decadencia cultural de la sociedad de masas configuran una extraña coincidencia.

Jesús Martín Barbero

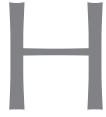

ay una trampa al comparar un documento programático tan general como es un plan de gobierno con un documento de carácter más específico que además tiene como sustento un diagnóstico ${ }^{4}$ de los posicionamientos sobre la cultura y el consumo cultural del país (CONCULTURA, 2007). Sin embargo, como un ejercicio académico creo que, salvando las distancias, se puede iniciar una discusión más amplia sobre las fronteras y los límites de lo cultural.

Dos propuestas quisiera resaltar del documento del FMLN. La pri- mera es la posibilidad de elevar a rango ministerial la institucionalidad que se encarga del ámbito cultural, lo que conlleva a reconocer la urgencia de una reingeniería y a la readecuación no solo de la partida presupuestaria gubernamental, que es una de las grandes debilidades, sino de la estructura misma, por ahora dividida en cuatro direcciones que responden a una visión clásica de la gestión cultural. La segunda es que en sus políticas se señala nuevamente la necesidad de un nuevo diagnóstico para la cultura y un nuevo proceso de concertación nacional sobre un tema que, 
con todo, sigue estando pendiente en la agenda.

Ambos documentos constituyen un paso fundamental en la discusión sobre lo cultural y sus implicaciones. El documento gubernamental se elabora a partir de cuatro campos de acción: producción y memoria, descentralización y transnacionalización, participación y acceso a la cultura, e institucionalidad cultural. El documento del FMLN se compone de un objetivo y doce políticas de acción. No explicaré el abordaje de dichos documentos, sino que me ocuparé directamente de señalar los puntos en común y a partir de ello puntualizar algunos ámbitos que no son tomados en cuenta.

Un primer punto que encuentro diluido en ambos documentos es la recuperación de una de las dimensiones fundamentales de la cultura, que es el ámbito simbólico de la vida social. En el documento de CONCULTURA se hace énfasis en el aspecto de la economía, en el del FMLN se insiste en los ámbitos modernos (creatividad, antropología, lingüística, arqueología, historia, arte, disciplinas constituidas en la división instaurada desde el XVII y que Wallerstein reseña de manera tan clara), pero no se anota de manera evidente, visible, que la cultura pasa por los procesos simbólicos y es desde ahí donde se juega la capacidad de representación, del vínculo entre los ciudadanos y del sentimiento de pertenencia a una comunidad. No hay una referencia al ámbito de la comunicación, de los procesos más masificados de la cultura, los que llevan a niveles a veces exasperantes de consumo, pero al mismo tiempo los más cotidianos y desde los cuales mucha de la población salvadoreña construye sentido. Por otro lado, en el mismo documento estatal poco se dice de cómo en el ámbito de la economía están, por un lado, las ganancias que efectivamente genera la cultura, pero por el otro hay un valor agregado que tiene que ver con cómo esta construcción de vínculos y ciudadanía desde lo simbólico finalmente repercute bajando los índices de violencia, de inseguridad, etc., lo que repercute también en el ámbito más formal de esta.

Ambos documentos hacen alusión a la memoria y la historia como un ámbito constitutivo de la identidad cultural. El documento del FMLN hace un énfasis en rescatar las culturas vivas y sobre todo revalorizar el acervo cultural de los pueblos naturales, como la raíz, una visión esencialista donde la nación se construye desde un pasado común. En este sentido la nación imaginada (Anderson, 2006) es una que fue, pero que ya no existe. Ambos documentos hacen un énfasis importante en los procesos de los creadores culturales y la necesidad de que sean capacitados. Sin embargo, no se vuelve visible, en ninguna de estas propuestas, la necesidad de que todas y todos los ciudadanos devengan creadores, constructores de sus propias narrativas. Es decir, si bien hay personas 
que dedicarán un tiempo mayor de su vida a la creación artística, de alguna manera todos podemos disfrutar de apropiarnos de nuevas narrativas y contar nuestras propias historias, documentar los procesos locales y las vivencias colectivas.

Más que hablar de cómo se tiene que trabajar en apuntalar la identidad cultural (en singular) es importante introducir la discusión sobre las múltiples y diversas identidades culturales que, sin embargo, nos van llevando a puntos de encuentro, o a una figura mayor a partir de los muchos colores y formas, al mejor estilo de la imagen de constelación de Walter Benjamin.

Hay un ámbito que ambos planteamientos han dejado de lado y que me parece fundamental: las industrias culturales. Independientemente que se esté o no de acuerdo con esta categoría acuñada por la Escuela de Frankfurt, no es posible establecer una discusión cultural seria sin pasar por lo que Jesús Martín Barbero y German Rey han señalado como el mal de ojo de los intelectuales (1999). Esto es la constante distancia que se mantiene hacia los medios masivos, en particular, de la televisión. En el documento del FMLN hay una alusión que explica que hay que "democratizar, reencauzar y fortalecer los medios de comunicación del Estado y los medios de comunicación comunitarios a nivel nacional", se dejan de lado los medios comerciales que tienen una gran influencia en la población. Es necesario considerar, en este sentido, el fortalecimiento (quizá más bien la construcción) de las industrias culturales nacionales que permitan justamente producir, crear, rescatar la memoria, transnacionalizar y acceder desde muchos ámbitos a una narrativa cultural propia que nos permita construir las distintas identidades culturales salvadoreñas. Si bien en ambos documentos hay menciones sobre la comunidad salvadoreña en el exterior, será bueno establecer acciones más claras en relación con esta corresponsabilidad en la construcción de la simbología cultural y la identidad de la nación.

Comprender las lógicas administrativas, industrializadas de la cultura también implica discutir y tener muy presentes lo que sucede con los tratados de libre comercio y la relación cultural en un mundo que cada vez se nos vuelve más abarcable. El documento de CONCULTURA trabaja el tema de la descentralización y transnacionalización; creo que un punto (a futuro) que debe ser discutido es la manera cómo los tratados de libre comercio que El Salvador ha firmado conllevan una cierta gestión del conocimiento y el tema de los derechos de autor. En un territorio descentralizado y transnacional, estos dos ámbitos son fundamentales en la discusión sobre lo cultural y no son tomados en cuenta en ninguno de los documentos.

Ambos documentos hacen énfasis en dos actores al señalar la participación y acceso a la cultu- 
ra: niños y jóvenes. Sin embargo, de nuevo esta visión se vuelve tradicional y no se nombran otros actores sociales que seguramente pueden disfrutar muy bien de la cultura, pienso en los jubilados (los memoriosos, los que llevan nuestra historia y que entrando en contacto con las nuevas generaciones pueden ayudar a construir una sociedad más tolerante), los indígenas (no solo como "guardianes de una parte de nuestras raíces", sino como actores cotidianos con sus propias lógicas, tiempos, cosmovisiones, invisibilizados en muchos momentos desde las discusiones de la cultura y más bien reducidos al ámbito de lo popular), la gente con capacidades especiales que muchas veces encuentra a través del arte otras maneras de contarnos quiénes son, y otros grupos más que si bien no son los protagónicos pues pueden ser mencionados. El documento de CONCULTURA hace además un énfasis fundamental en la necesidad de rescatar la lectura. Igual que lo que sucede con los actores, también resulta fundamental que se haga mención de la necesidad de construir nuevas narrativas desde los múltiples lenguajes que tenemos. La necesidad de rescatar nuestra tradición oral y de darle su lugar y su valor (festivales de contadores de cuentos, fiestas tradicionales, teatros populares, radios comunitarias que sí son mencionadas estas últimas en el documento de la izquierda), la importancia de construir nuestros propios discursos audiovisuales, hipertextuales, etc.

Si bien hay ciertos énfasis en cada documento, parece que los puntos de partida son los mismos. Una concepción de cultura que señala las artes constituidas en el siglo XIX, pero que no coloca en discusión la construcción simbólica que se produce a partir de los medios de comunicación. Una reflexión que considera la cultura de masas como una amenaza y que más bien prefiere ir hacia las culturas originarias, los valores, los pueblos naturales, una concepción que se enraíza en el pasado y no en el presente, que se preocupa por la pérdida más que por las nuevas construcciones estéticas. Una apuesta que todavía necesita discutir con Adorno si la decadencia de la cultura es su puro llegar a sí misma.

\section{Decálogo de reflexiones iniciales}

\begin{abstract}
- Ce puede ir más allá de 2 las concepciones ilustra$C$ das tradicionales sobre la cultura, la estética y su-lugar-en-lasociedad? ¿Se puede construir una propuesta alternativa y distinta sobre
\end{abstract}

lo cultural, sobre la experiencia estética? La discusión tendría que empezar por plantearnos, más allá de visiones patrimonialistas o ilustradas sobre la cultura. En diálogo con las propuestas éticas y estéticas, propongo esta 
primera provocación de un decálogo que condense las agendas urgentes sobre la reflexión cultural.

\section{Ganarse el derecho a la escucha.}

Se habla mucho del derecho a la palabra, a decir, la libertad que sigue siendo considerada uno de los bienes más preciados. Poco se dice, sin embargo, que también es fundamental el derecho a la escucha, un derecho que se conquista, que se gana. Esta imagen me parece interesante. Pues coloca un reto fundamental para quienes trabajamos temas relacionados con la cultura: posicionar el tema cultural. Nadie comprenderá la importancia de esta discusión si no se inicia y, despojándose de arrogancias y malentendidos, se consigue el derecho a la escucha y se coloca en la agenda de discusión el ámbito de lo cultural.

\section{La cultura es ordinaria.}

Se tiene en muchos momentos la tentación de mantener la visión moderna e ilustrada de la cultura. Sin embargo, si se quiere colocar el tema en la discusión de la sociedad es necesario recordar, junto con Raymond Williams (1999), que si bien el término cultura es uno de los más difíciles de definir o con Bauman (2002) que hay varias definiciones que convergen en un mismo significante; vale insistir que la cultura es ordinaria, se constituye desde la vida cotidiana y su centralidad. Si una herencia nos pueden dejar las vanguardias (y la reflexión de otros teóricos, como los frankfurtianos o el mismo Brecht) es que el arte tiene mucho que decir a la vida y si permitimos este diálogo, encontraremos nuevos caminos para los procesos emancipatorios que siguen siendo urgentes en Centroamérica.

\section{Más que "enseñarse", la cultura debe reflexionarse desde su cons- trucción en los procesos educativos.}

Un aporte fundamental que desde la academia y los ámbitos de la educación formal pueden llevarse a cabo. La discusión de cómo se sitúa la reflexión sobre lo cultural, cómo se constituye espacio dinámico, cambiante, en permanente construcción y cómo desde la escuela se debe aprender a construir significados, a contar sus propias narrativas, identidades, historias y memorias. Es fundamental revisar experiencias para la valoración de las diversas culturas.

\section{Recuperar la dimensión estética} de la vida y esto implica recuperar la experiencia dinosíaca que tan desdibujada se encuentra en sociedades como las nuestras (Nietszche lo señaló de manera contundente). $\mathrm{Si}$ bien en las sociedades del primer mundo ya se habla de los derechos al goce y al disfrute, en nuestros países todavía parece existir (como lo señaló el chileno Norbert Lechner en el informe de desarrollo humano Así somos nosotros, los chilenos) una especie de reserva o de escrúpulo en admitir y posibilitar procesos que constituyan las experiencias del goce.

\section{Recuperar la dimensión política} de la cultura implica situar la discusión sobre los reconocimientos 
no solo de los otros negados, sino también los diferentes lenguajes y estéticas que no han sido consideradas o que durante mucho tiempo han sido invisibilizadas. Las estéticas indígenas y afroamericanas. Los lenguajes de la televisión e Internet. La cocina, las corporalidades, los olores. Los discursos de nación operan desde la homogenización y se construyen en mucho desde la negación de las diferencias y la afirmación de un otro.

\section{El derecho a la memoria es el derecho también al olvido.}

No se trata solo de lo que se recuerda, sino también de esas temporalidades inconclusas que construyen la memoria. ¿Quién recuerda y qué es lo que se recuerda? Es terminar de una vez con las visiones más estructuralistas y tradicionales de la interpretación de la memoria histórica, que no es lo que realmente pasó, sino la manera cómo se construye en una triple mímesis que reconstruye sentidos. Pensar la cultura implica, con Paul Ricoeur, pensar "el inquietante espectáculo que produce la demasiada memoria acá y el demasiado olvido allá". De estas operaciones está constituida la identidad salvadoreña.

\section{Pensar el patrimonio como "capital cultural".}

Desde la propuesta del sociólogo francés Pierre Bourdieu, implica que el patrimonio puede ser expropiado de sus antiguos dueños para ser devuelto a los sectores populares y resignificado, investido de nuevos va- lores. Implica comprender que lo que hemos constituido como patrimonio cultural actual obedece a largos procesos de negociación de sentido.

\section{La cultura implica dinámicas de} mercado en las que está inmersa, es fundamental recuperar uno de los conceptos clave que nos legó la Escuela de Frankfurt y entender las nuevas lógicas industriales y globales a las que se debe. Es también clave en este sentido rescatar la propuesta de George Yúdice (2002) y comprender que la cultura es un recurso y que como tal implica pensar procesos de administración y regulación intencionados.

\section{La cultura es, también, ciencia y técnica.}

Es recuperar la concepción de tekné en este sentido amplio señalado por la tradición griega. Hoy más que nunca la cultura no puede ser pensada sin esa nueva tecnología de Internet que nos ha construido y ha hecho que la cultura devenga mundo, que constituye nuevos lenguajes, narrativas, estéticas y actores que desde este espacio colectivo, desde esta nueva plaza pública construyen propuestas estéticas y simbólicas. Esta relación supone también una renegociación de los derechos de autor y la manera como se ha venido abordando.

10. Pensar el reconocimiento implica situarnos en el ámbito de la traducción. Si bien Benjamin advierte sobre los peligros de este ejercicio, Ricoeur insistirá en que en esta posibilidad se juega el re- 
conocimiento de la diversidad simbólica. Jesús Martín Barbero señala que hay un largo camino que va del desconocimiento al reconocimiento, y del reconocimiento de sí al reconocimiento mutuo; para ello la narración es fundamental pues toda identidad es algo que se narra. En

\section{BibLiografía}

Anderson, B. Comunidades Imaginadas. México D.F.: FCE

Bauman, Z. (2002). La cultura como praxis. Barcelona: Paidós.

Bourdieu, La distinción. Criterio y bases sociales del gusto. México D.F.: Taurus.

Concultura (2007). Resultados consolidados del Diálogo Nacional por la Cultura. San Salvador: Concultura

Concultura (2008). El Salvador. La cultura: una apuesta nacional. San Salvador: Concultura/ PNUD/OEI.

Martín Barbero, J. (1998) De los medios a las mediaciones. Comunicación, cultura y hegemonía. Bogotá: Convenio Andrés Bello.

Martínez, G. (coord.). Cambio en español es ilustrativa la diversidad de sentidos del verbo contar es narrar historias, ser tenido en cuenta y hacer cuentas, desde esta polisemia se colocan los ámbitos fundamentales de la inclusión.

$$
\text { San Salvador, abril-mayo de }
$$
2009

El Salvador para vivir mejor: Plan de gobierno 2009- 2014. Disponible en: http://www. fmln.org.sv/fmlnORG/archivos/ file/2008/gobierno\%20del\%20 cambio.pdf. Recuperado el 5 de diciembre de 2008.

Rey, G. y Martín Barbero, J. (1999). Los ejercicios del ver. Hegemonía visual y ficción televisiva. Barcelona: Gedisa.

Ricoeur (2004). La memoria, la historia y el olvido. Madrid: Trotta.

Wallerstein, I. (coord.) (1997) Abrir las ciencias sociales. ( $2^{\mathrm{a}} \mathrm{ed}$.). México D.F.: Siglo XXI.

Williams, R. (1999). Sociología de la cultura. Barcelona: Paidós.

Yúdice, G. (2002). El recurso de la cultura. Barcelona: Gedisa.

\section{NOTAS}

1. El documento fue presentado el 24 de octubre de 2008, en el Museo Nacional de Antropología. El evento no fue reseñado por los grandes medios del país.

2. Se habla de reformas económicas, sociales y políticas, y de gestión ambiental como los cuatro grandes temas destacados.

3. El arte por el arte, desvinculada casi de la vida cotidiana.

4. Criticado en ciertos espacios, sobre todo académicos, por su metodología y su parcialización en algunos ámbitos; pero diagnóstico al fin, punto de partida y hoja de ruta que tuvo discusiones con distintos actores del ámbito de lo cultural. 